\title{
Keratin-Graphene Nanocomposite: Transformation of Waste Wool in Electronic Devices
}

DOI:

10.1021/acssuschemeng.9b02415

\section{Document Version}

Accepted author manuscript

Link to publication record in Manchester Research Explorer

\section{Citation for published version (APA):}

Cataldi, P., Condurache, O., Spirito, D., Krahne, R., Bayer, I., Athanassiou, A., \& Perotto, G. (2019). KeratinGraphene Nanocomposite: Transformation of Waste Wool in Electronic Devices. ACS Sustainable Chemistry and Engineering. https://doi.org/10.1021/acssuschemeng.9b02415

\section{Published in:}

ACS Sustainable Chemistry and Engineering

\section{Citing this paper}

Please note that where the full-text provided on Manchester Research Explorer is the Author Accepted Manuscript or Proof version this may differ from the final Published version. If citing, it is advised that you check and use the publisher's definitive version.

\section{General rights}

Copyright and moral rights for the publications made accessible in the Research Explorer are retained by the authors and/or other copyright owners and it is a condition of accessing publications that users recognise and abide by the legal requirements associated with these rights.

\section{Takedown policy}

If you believe that this document breaches copyright please refer to the University of Manchester's Takedown Procedures [http://man.ac.uk/04Y6Bo] or contact uml.scholarlycommunications@manchester.ac.uk providing relevant details, so we can investigate your claim.

\section{OPEN ACCESS}


Subscriber access provided by AUB Libraries

\section{Article}

\section{Keratin-Graphene Nanocomposite: Transformation of Waste Wool in Electronic Devices}

Pietro Cataldi, Oana Condurache, Davide Spirito, Roman Krahne, Ilker S. Bayer, Athanassia Athanassiou, and Giovanni Perotto

ACS Sustainable Chem. Eng., Just Accepted Manuscript • Publication Date (Web): 19 Jun 2019

Downloaded from http://pubs.acs.org on June 19, 2019

\section{Just Accepted}

"Just Accepted" manuscripts have been peer-reviewed and accepted for publication. They are posted online prior to technical editing, formatting for publication and author proofing. The American Chemical Society provides "Just Accepted" as a service to the research community to expedite the dissemination of scientific material as soon as possible after acceptance. "Just Accepted" manuscripts appear in full in PDF format accompanied by an HTML abstract. "Just Accepted" manuscripts have been fully peer reviewed, but should not be considered the official version of record. They are citable by the Digital Object Identifier (DOI®). "Just Accepted" is an optional service offered to authors. Therefore, the "Just Accepted" Web site may not include all articles that will be published in the journal. After a manuscript is technically edited and formatted, it will be removed from the "Just Accepted" Web site and published as an ASAP article. Note that technical editing may introduce minor changes to the manuscript text and/or graphics which could affect content, and all legal disclaimers and ethical guidelines that apply to the journal pertain. ACS cannot be held responsible for errors or consequences arising from the use of information contained in these "Just Accepted" manuscripts. 


\title{
Keratin-Graphene Nanocomposite: Transformation of
}

\section{Waste Wool in Electronic Devices}

\author{
Pietro Cataldi ${ }^{1+*}$, Oana Condurache ${ }^{\dagger}$, Davide Spirito $\neq$, Roman Krahne $\neq$, llker S. Bayer \\ ${ }^{\dagger}$, Athanassia Athanassiout ${ }^{*}$, Giovanni Perotto ${ }^{+*}$ \\ tSmart Materials Group, Italian Institute of Technology, Via Morego 30, Genova \\ 16163, Italy \\ ¥Optoelectronics Group, Italian Institute of Technology, Via Morego 30, Genova \\ 16163, Italy
}

\section{Present Addresses}

'National Graphene Institute, University of Manchester, Booth Street East, Manchester M13 9PL, United Kingdom

Keywords: Waste-based Electronics; Sustainable Electronics; Circular Economy Electronics; Protein-based Electronics; Graphene; Green Manufacturing ${ }^{*}$ Corresponding authors: pietro.cataldi@manchester.ac.uk,
athanassia.athanassiou@iit.it, giovanni.perotto@iit.it

\begin{abstract}
Electronic devices, designed to be long lasting, are commonly made with rigid, nondegradable materials. This, together with the presence of rare and toxic elements, creates significant issues for their waste management. The production of electronic devices, made with biodegradable materials that are sourced from waste streams of the agricultural sector, will create the premises for circular economy systems in the electronics sector that will increase its sustainability. Here, this new approach has been demonstrated by using keratin, the protein extracted from waste wool clips, combined with graphene to produce protein-based electronic materials. Resistors plane capacitors and inductors were fabricated, characterized and then assembled together to obtain analogue electrical circuits, such as, high-pass filters or resonators. Morphological structures, electrical characteristics, thermal stability and mechanical properties were fully investigated. Finally, a water-based ink of keratin and graphene was used to functionalize cellulose, obtaining flexible electrodes with remarkable sheet resistances $(\approx 10 \Omega / \mathrm{sq})$, ohmic I-V curves were obtained and the electrical conductivity after folding/unfolding cycles was measured. All the processing and fabrication methods used water as the only solvent. The described approach produced easily disposable electronics materials with reduced fingerprint on the environment, demonstrating that keratin from wool waste is an excellent candidate for the creation of circular economy systems in the electronics sector. The proposed valorization of waste materials for electronics applications is named "wastetronics".
\end{abstract}




\section{Introduction}

The massive use of electronic devices generated enormous societal development and economic growth opportunities but their complications in terms of sustainability and end of life management are becoming more and more evident. ${ }^{1,2}$ The worldwide annual generation of electronic waste (e-waste) is forecasted to reach 50 million tons in 2020, and is the fastest growing class of waste..$^{3,4}$ Electronics materials are mostly long-lasting, precious, rare and sometimes even toxic. ${ }^{5,} 6$ Therefore, e-waste management is becoming predominant in the governments' priorities. ${ }^{3,6} \mathrm{~A}$ totally different alternative, that relies on the manufacturing of disposable and degradable electronic devices fabricated using sustainable and biodegradable materials and green fabrication methods, has recently gained attention. ${ }^{7,8}$ From the various sources of sustainable and biodegradable materials, agricultural waste is considered the most important candidate. ${ }^{9}$

Here, we report on the development of a new generation of disposable electronic components and devices based on keratin extracted from waste wool clips that were discarded by the textile industry. Wool waste, and in more general regards, keratinaceous waste, with 5 million tons produced yearly in the EU can be an important source of renewable and biodegradable materials. ${ }^{10}$ Keratin, the main protein constituting keratinaceous tissues, describes a class of structural proteins that provide mechanical strength and toughness, thanks to their fibrillary arrangement and extensive disulphide crosslink. ${ }^{11}$ Keratins have been studied as materials for a variety of applications: from biomedical ${ }^{12,13}$ to packaging ${ }^{14}$ to functional materials. ${ }^{15}$ The two most important sources of keratinaceous waste are wool clips and chicken feathers. Specifically in this paper, keratin from wool was selected because of its easier 
availability. Given the similarities between keratin from wool and chicken feathers, results presented here will be easily translated to other keratins.

The development of technologies for the transformation of agricultural waste into electronic materials could have the dual benefit of creating new and valuable opportunities for the waste valorization into high added-value materials, and, simultaneously, contributing to the development of more sustainable electronics. Components and devices based on keratin will boost circular economy approach in the electronics sector and inspire a new generation of easily disposable electronics products with reduced fingerprint on the environment.

\section{Materials}

Raw wool clips from sheep were kindly provided by Olimpias spa (Ponzano Veneto, Italy). Silk cocoons were provided by CREA, Padova, Italy. Polyglycerol (POLYGLYCERYL 10) was kindly provided by Spiga Nord spa (Carasco, Italy). Graphene nanoplatelets (GnPs) are provided by Directa Plus (grade Ultra $\mathrm{G}+$ ), Lomazzo, Italy. For details on lateral size, thickness and Raman spectra of the nanoflakes see this previous report. ${ }^{16}$ The Porous Cellulose Networks (PCN, approx. $40 \mu \mathrm{m}$ thick, pores of tens of $\mu \mathrm{m}$ ) are acquired from Kimberly-Clark® (Kimtech Science Precision Wipes, Art. Num. 05511). PVP (polyvinylpyrrolidone) 360000 Da, LiBr, Urea, SDS (sodium dodecylsulfate), 2-mercaptoethanol, were purchased from Sigma Aldrich. Dialysis membrane, 3500 MWCO, were purchased from SpectraPor. Ultrapure water $(18.2 \mathrm{M} \Omega . \mathrm{cm})$ was used as the only solvent for the experiments.

\section{Preparation of the keratin solution}

Keratin was extracted from the wool fibers following a previously published protocol. ${ }^{17}$ Briefly, the as received wool fibers were cleaned overnight using a 1:1 solution of 
methanol and acetone under agitation. Fiber were then rinsed with clean solvents twice and washed with MilliQ water twice. Cleaned fibers were allowed to dry overnight at room temperature. Keratin was extracted from the cleaned wool fibers with a water solution containing 7 M Urea, 0.05 M SDS and 1.1 M 2-mercaptoethanol. Eighteen ml of solution were used per each gram of cleaned wool fibers. The extraction was performed at $60^{\circ} \mathrm{C}$ for 5 hours. The solution was then filtered with a 50 mesh stainless steel grid to eliminate undissolved wool fibers and the resulting solution was dialyzed against MilliQ water for three days with 7 water changes, using a 3500 MWCO membrane. The resulting solution was centrifuged for $20 \mathrm{~min}$ at $9000 \mathrm{~g}$ at $5^{\circ} \mathrm{C}$ to remove fiber residues. This procedure allowed to obtain 0.6 grams of keratin per gram of wool clips used. The protein concentration was measured by drying a known volume of the solution. The concentration of the keratin solution was increased to $90 \mathrm{mg} / \mathrm{ml}$ by partial evaporation of the water, in order to achieve the viscosity needed for specific sample preparation.

\section{Preparation of the keratin and graphene ink}

The dispersions of keratin and GnPs were prepared adding to the protein solution different weight percent of GnPs. Different compositions were obtained by adding various amount of $\mathrm{GnP}$ powder to the protein solution and vigorously sonicating with a tip sonicator (Sonics \& Materials, Inc., Model Num. VCX750) to obtain homogeneous dispersion. The concentrations, expressed as weight percent (wt.\%) of GnPs, are relative to the weight of the keratin in a dry basis. To improve the dispersion of GnPs, up to $5 \mathrm{mg} / \mathrm{ml}$ of PVP (polyvinylpyrrolidone) were added and dissolved before GnPs inclusion. 
As an example, the typical preparation for the $30 \mathrm{wt} \%$ GnPs loaded sample is in the following. $16 \mathrm{ml}$ of $90 \mathrm{mg} / \mathrm{ml}$ water keratin solution are mixed with $80 \mathrm{mg}$ of PVP and afterwards $430 \mathrm{mg}$ of $\mathrm{GnPs}$ are added to the resulting solution. The dispersion is then tip sonicated ( $750 \mathrm{~W}, 40 \%$ Amplitude, $20 \mathrm{kHz}, 3$ times for 1 minute).

\section{Resistors Preparation}

$2 \mathrm{ml}$ of the keratin-GnPs ink were drop casted on polydimethylsiloxane (PDMS, size 4 cm2) mould. After evaporation, diverse resistors were obtained depending on the amount of GnPs employed.

\section{Silk Fibroin dielectric films}

The preparation of silk dielectric films was performed by casting a water solution of silk fibroin on PDMS mould. The silk fibroin water solution was obtained from silk cocoons following the procedure reported by Rockwood. ${ }^{18}$

\section{Capacitors Preparation}

Freestanding capacitors were assembled using conductive keratin-GnPs electrodes (30 wt.\% of GnPs) and freestanding pure keratin film or freestanding pure silk fibroin films as dielectric. The capacitor was assembled after softening the constituent layers by conditioning in high humidity environment (close to $100 \% \mathrm{RH}$ ) for $10-20$ minutes. Keratin and silk fibroin acquire flexibility and sticking properties after moisture conditioning. Consequently, a simple hot-plate pressing $\left(\approx 80^{\circ} \mathrm{C}\right.$ at the top of the hot plate) was sufficient to glue the electrodes on both sides of the dielectric layer. The pressure exerted is of about $160000 \mathrm{~Pa}$. PDMS layers is used in order to distribute the pressure uniformly and to prevent sample ruptures with pressure.

\section{Inductors Preparation}


Using a $40 \mathrm{~cm}$ ribbon of the conductive keratin composite a protein-based inductor was fabricated. To facilitate wrapping of the conductive strip on the dielectric core, a small amount of POLYGLYCERYL (5\% wt.) was added to the biocomposite before casting and the sample was conditioned in high humidity before wrapping. POLYGLYCERYL, a polymer of glycerine, acts as a plasticizer for keratin thanks to its humectant properties. When conditioned in a high humidity environment, the biocomposite became extremely soft and flexible, allowing it to be wrapped around a cylinder with a curvature radius of only $2 \mathrm{~mm}$ with no cracks or damage. Once the material was equilibrated at ambient temperature and humidity, it was able to retain the shape it was given. Solenoids were realized with 2 turns per $\mathrm{cm}$ with up to 18 turns.

\section{Cellulose-based Electrode Preparation}

The flexible cellulose-based samples were prepared drop casting a diluted keratinGnPs solution on top of cellulose substrates and fast-drying with a heat-gun $\left(80-100^{\circ} \mathrm{C}\right.$ on the cellulose surface). As an example, the typical preparation for the $30 \mathrm{wt} \% \mathrm{GnPs}$ loaded cellulose sample was the following: $27 \mathrm{mg}$ of $\mathrm{GnPs}$ were added to $18 \mathrm{ml}$ of a $5 \mathrm{mg} / \mathrm{ml}$ keratin solution, the dispersion was then tip sonicated as previously described. The as-obtained conductive ink was slowly drop casted in equal amount on both sides of a $(7.5 \times 5) \mathrm{cm}^{2}$ cellulose substrate and heat gun dried. Teflon films (Advent Research Material, Art. Num. FP823338) were placed under the cellulose substrate to avoid leaking of the water-based conductive ink out from the cellulose substrate and ensure its impregnation.

\section{Methods}

All the measurements were performed on minimum 4 different samples unless specified differently. 


\section{Electron Microscopy}

The SEM images of the morphology and of the cross section of the specimens were acquired with a JEOL microscope (model JSM-6490LA) operating at an acceleration voltage of $5 \mathrm{kV}$. The films for cross-sectional SEM images were fractured at liquid nitrogen temperature $\left(-195.79{ }^{\circ} \mathrm{C}\right)$ by tearing them with two tweezers, reducing the deformation of the samples.

\section{Profilometry}

The surface roughness of the keratin-GnPs films was measured by optical profilometry using a Zeta-20 optical profilometer (Zeta Instruments, USA). Roughness was calculated by averaging four different $500 \mu \mathrm{m} \times 660 \mu \mathrm{m}$ images.

\section{Sheet Resistance Characterization and Folding Stability}

The sheet resistance measurements were performed with a four-probe resistance system (Keithley 2611A sourcemeter). Silver paste (SPI Conductive Silver Paint) electrodes of $5 \mathrm{~mm}$ were realized on the specimens with $5 \mathrm{~mm}$ spacing between the contact points.

$0 \mathrm{~mm}$ bending radius folding-unfolding cycles were performed, as previously reported, 19,20 on the samples and the resistance variation is measured across the fold mark. A cylindrical weight of approximately $2 \mathrm{~kg}$ was pressed on the folding edge during the folding cycle to increase the stress exerted on the material.

\section{Impedance Characterization}

For impedance measurements, we employed small drops of silver paste and Al foil to create contacts to the devices. They were then fixed on a plastic support for easier handling and mounted in a probe station. The impedance was measured in the range 
$100 \mathrm{~Hz}-300 \mathrm{kHz}$ with an LCR meter (Keysight E4980AL); we used the instrument correction functions to compensate for error due to parasitic impedance and admittance due to cabling and connections. The electrical properties of free-standing capacitors have been measured by an autobalancing bridge method. An alternating input voltage with an amplitude of 0.1 Vrms was applied.

\section{Thermogravimetric Analysis}

Thermogravimetric analysis (TGA) of the films was performed using a TA instruments machine (model Q500) in N2 flow and increasing the temperature in the chamber from ambient to $800^{\circ} \mathrm{C}$ using a heating rate of $5^{\circ} \mathrm{C} / \mathrm{min}$.

\section{LEDs Preparation}

The LED chips were prepared employing 10 Cree lights components (model CLP6, 4.4 V, $32000 \mathrm{mlm}$, white). They were assembled on copper plates resembling IIT logo. The voltage applied to light them up through the cellulose based conductor was $12 \mathrm{~V}$.

\section{Mechanical Characterization}

A uniaxial testing machine (Instron 3365) was used to measure the mechanical properties of the cellulose-based biocomposite and of the raw materials (initial length $25 \mathrm{~mm}$, width $4 \mathrm{~mm}$, deformation rate $2 \mathrm{~mm} \mathrm{~min}^{-1}$ ).

\section{Results}

\section{Keratin and graphene ink to make keratin resistors}

The first step required the coupling of keratin proteins with conductive nanomaterials. This was achieved by obtaining first a water solution of keratin, as described in detail in the materials and method section, in which graphene nanoplatelets (GnPs) could be dispersed. After extraction from the waste wool clips, the keratin solution appeared 
transparent, as shown in the scheme of Figure 1a. Different compositions were obtained by adding various amounts of GnPs powder to the protein solution, in which a small amount of polyvinylpyrrolidone (PVP, $360 \mathrm{kDa}$ ) was added to improve dispersion of the GnPs, and vigorously sonicated. The water/keratin dispersion of GnPs appeared homogeneous, with only a negligible amount of GnPs settling after 24 hours. Even after being stored for weeks, the solution could be made homogenous again by tip sonication. The zeta potential of the single components of the ink, reported in Table S1, show that the use of PVP and keratin allowed to create a stable suspension of GnPs in water.

Freestanding conductive samples were subsequently fabricated by drop casting 90 $\mathrm{mg} / \mathrm{ml}$ keratin solution, with $5 \mathrm{mg} / \mathrm{ml}$ PVP and different amounts of GnPs, that was viscous enough to prevent and control the precipitation of the conductive nanofillers upon water evaporation (scheme of Figure 1a). Characteristics of the GnPs such as average lateral size, thickness and Raman spectra were previously reported. ${ }^{16,21}$ The surface of the freestanding samples, from a microscopic point of view, showed roughness of $2.2 \pm 0.2 \mu \mathrm{m}$, associated with the protrusion of GnP flakes, as seen in Figure $1 \mathrm{~b}$ and Figure $\mathrm{S} 1$. The cross section of the films, reported in Figure $1 \mathrm{c}$ and at higher magnification in Figure S2, shows that samples were between $100 \mu \mathrm{m}$ and 150 $\mu \mathrm{m}$ thick, with the GnPs homogeneously dispersed throughout the protein matrix. From a macroscopic point of view, the samples appeared flat, dense and homogeneous.

The percolation threshold was determined by measuring the sheet resistance of the protein nanocomposite for the different GnPs concentrations produced. ${ }^{22-24}$ The sheet resistance, plotted as a function of the GnPs loads in Figure 1d, shows that freestanding samples became electrically conductive at around 5 wt.\% GnPs 
concentration. Around this composition, the sheet resistance dropped five orders of magnitude from above $10^{10} \Omega / s q$ to $\sim 10^{5} \Omega / s q$, with samples displaying an ohmic I-V behavior (see Figure S3). The nanocomposites could become significantly more conductive by adding GnPs, easily reaching $\approx 10 \Omega / s q$ sheet resistances at 30 wt.\% filling factor. These highly conductive samples, can compete in terms of electrical performance with state of the art graphene-based composites. ${ }^{25}$ The control of the samples' conductivity, achieved by simply changing the graphene concentration, can be used to create resistors, whose resistance values can be tuned between few Ohms up to mega Ohms. 
a)
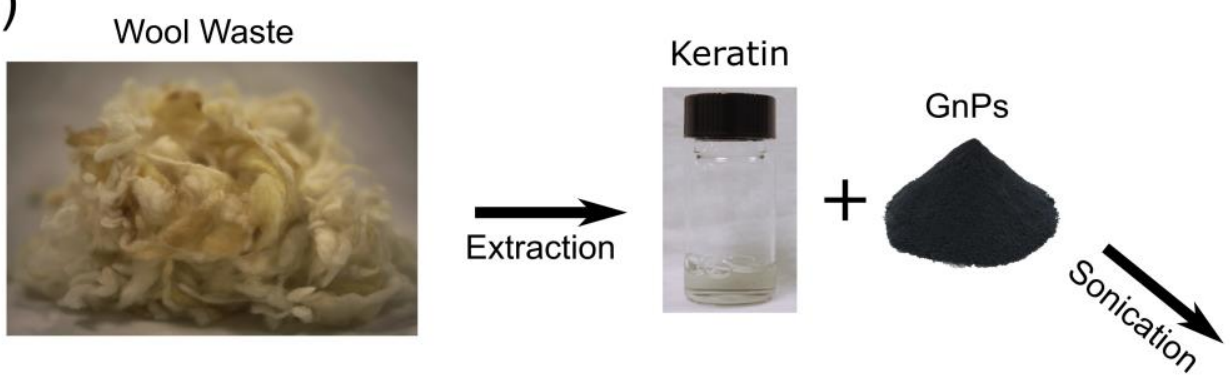

Water-based

Conductive Ink

Waste-based Conductor
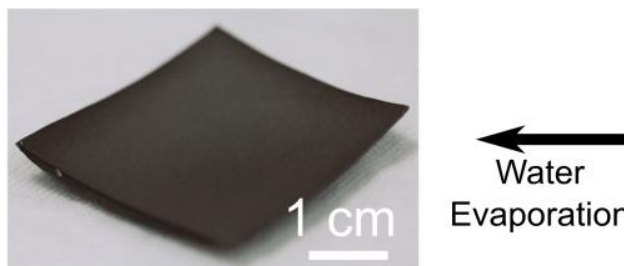

Evaporation
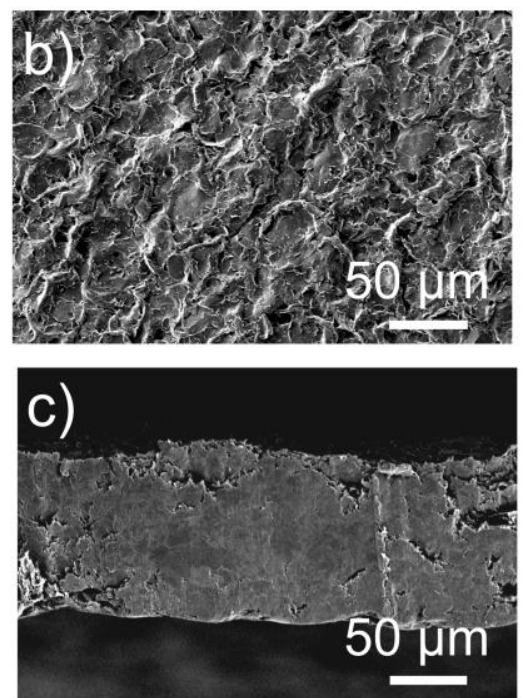

d)
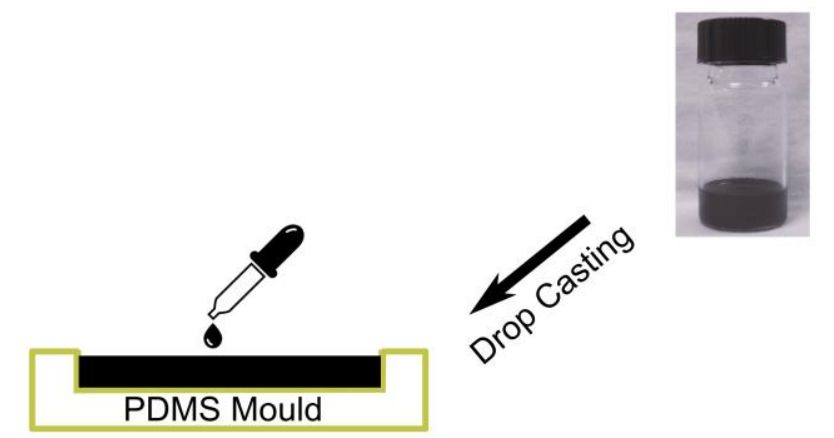

Figure 1: a) Fabrication scheme of the keratin-GnPs water dispersion and of the freestanding biocomposites; SEM images of b) the surface and c) the cross-section of the keratin-GnPs nanocomposite; d) sheet resistance of the samples versus concentration of GnPs (wt.\%).

\section{Preparation of the waste-based capacitor and inductors}

Another fundamental passive component for electronics is the capacitor. Commercial capacitors are generally realized with rigid, non-sustainable and non-degradable materials, whose composition and mechanical properties appear unsuitable for 
pioneering fields, such as epidermal, flexible, conformable, and/or transient electronics.

In this work we developed keratin protein capacitors, assembled in a planar configuration with two conductive keratin-GnPs electrodes (30 wt.\% GnPs concentration) and a protein dielectric. This dielectric layer was made from a freestanding film of pure keratin or a film of silk fibroin, the protein extracted from silk cocoons. Details on the preparation of the fibroin dielectric film and the assembly of the capacitors are reported in the supporting information. The capacitors were assembled according to the schematic presented in Figure 2a. The constituent layers were hot embossed together after conditioning the three layers in high humidity environment that was found to soften the materials and facilitate the adhesion (see the mechanical properties of the keratin film reported in Table S3). The impedance of the capacitors realized with the keratin dielectric showed a capacitive characteristic although with a phase shift between $-50^{\circ}$ and $-70^{\circ}$, hinting to a non-ideal behavior likely caused by a parasitic resistance. Capacitors realized with silk fibroin dielectric of $50-160 \mu \mathrm{m}$ in thickness exhibited a more ideal impedance, with $1 \mathrm{~cm}^{2}$ protein capacitor showing capacitances between 50 and $550 \mathrm{pF}$ and phases of $-85-87^{\circ}$. Other details on the capacitor characteristics, such as the real part of the impedance, the dielectric constant of the fibroin and the thickness and area of the capacitor are reported in Table S2. Macroscopic pictures and SEM images of the cross section of a representative capacitor are shown in Figure 2. The two electrodes formed a good adhesion with the dielectric layer without air pockets or short circuits, as it can be seed in the SEM images of Figures 2c. The adhesion of the keratin electrodes with the fibroin was long lasting: the capacitors were able to maintain their integrity and electrical performance after more than 6 months in ambient conditions. 
a)
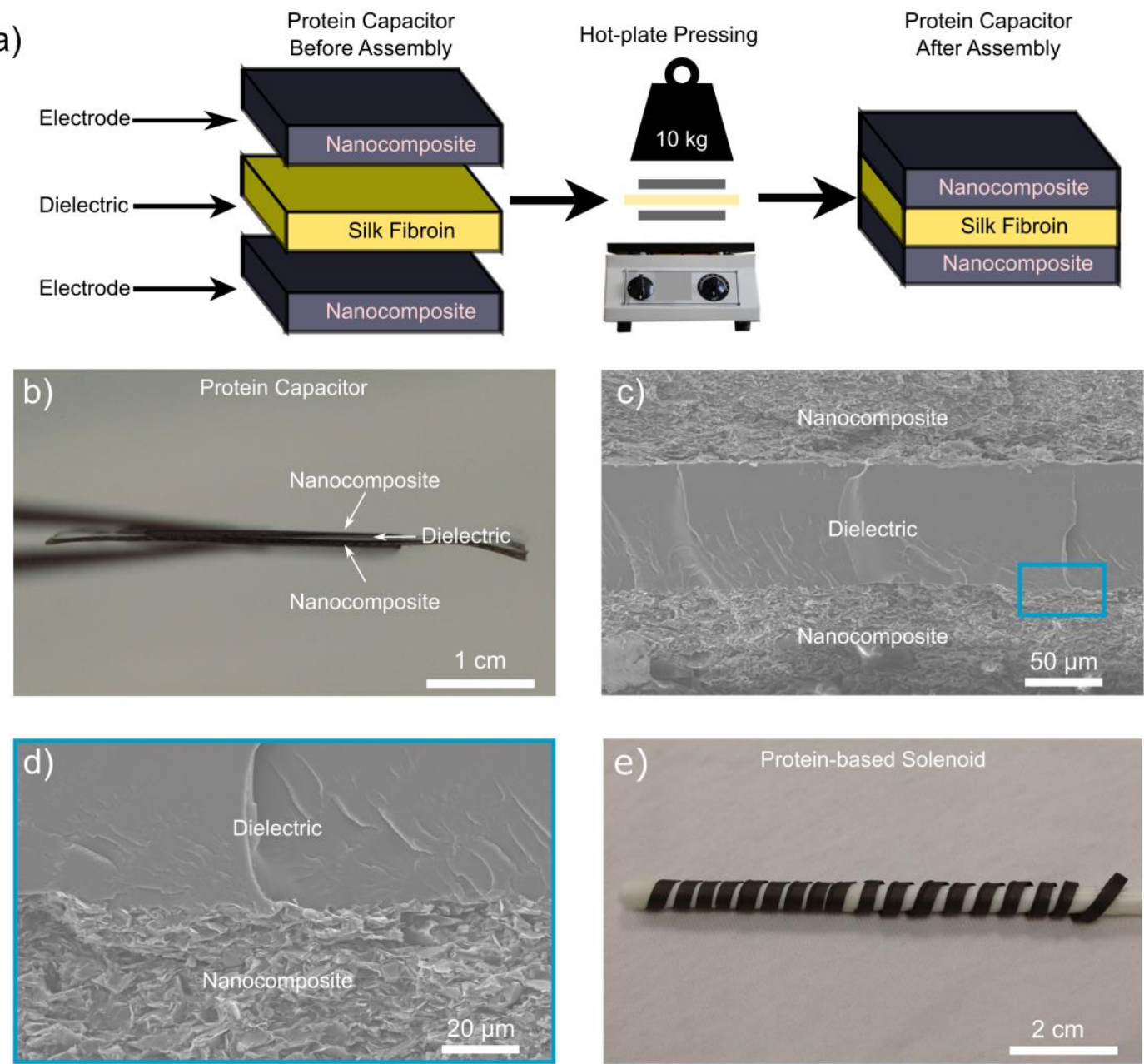

Figure 2: a) Fabrication scheme of the protein capacitor; b) photo of the protein capacitor; c) and d) SEM image of the capacitors' cross section morphology; e) photo of a typical inductor realized by wrapping the biocomposite electrode around an insulating cylindrical stick.

The third discrete component of analogue electronics is the inductor. Typically, inductors are formed by coils of metals, wrapped around a support (core) of insulating material. An inductor with solenoid geometry was fabricated using a $40 \mathrm{~cm}$ long strip of the conductive keratin composite. To facilitate wrapping of the conductive strip on the dielectric core, a small amount of Polyglycerol (5 wt.\%) was added to the biocomposite before casting and the sample was conditioned in high humidity before wrapping (see the mechanical properties of the keratin-based material in Table S3). Polyglycerol, a polymer of glycerine, acts as a plasticizer for keratin thanks to its humectant properties. When conditioned in a high humidity environment, the 
biocomposites became extremely soft and flexible, allowing them to be wrapped multiple times around a cylinder with a curvature radius of only $2 \mathrm{~mm}$, with no cracks or other types of damage. Once the material was equilibrated at ambient temperature and humidity, it was able to retain the shape it was given. Solenoids were realized with 2 turns per $\mathrm{cm}$ with a total of 18 turns. From a fabrication standpoint, this demonstrates that conformal electronics, even with complex shapes and forms, can be easily realized using the keratin-based materials.

\section{Characterization of basic analogue circuits}

With the discrete components fabricated, basic analogue circuits can be assembled. Resistors, capacitors and inductors can be combined to create filters, resonators, or integrator/differentiators. Figure 3a shows the impedance of the capacitor measured between $100 \mathrm{~Hz}-300 \mathrm{kHz}$; the magnitude follows the expected 1/f dependence where the phase is close to $-90^{\circ}$. The estimated capacitance (from the fit of the magnitude) is $86 \mathrm{pF}$. Analyzing the data in more details using a constant phase model $Z=Q /(j \omega)^{n}$ we found for the exponent $n$, a value of 0.9 . Such value is close to $n=1$, expected for an ideal device. The slight discordance might be the result of a not perfectly homogeneous electrode. ${ }^{26}$

When the capacitor was connected in series with a $40 \mathrm{k} \Omega$ nanocomposite resistor, as sketched in the inset of figure $3 b$, the circuit showed the characteristic behavior of a high-pass filter with cut-off frequency of $46 \mathrm{kHz}$, working as differentiator for frequency below the cut-off. In figure $3 b$ the output signal of a square wave input, is reported for various frequencies. At high frequency the square wave is only slightly distorted, while at low frequency a pulse-like waveform (i.e., the derivative of the square wave) is observed. Finally, the frequency response of the capacitor connected in series with an 
inductor is measured (Figure 3c). This LCR circuit exhibits a resonant behavior: at low frequency, it had a capacitive behavior (phase around $-90^{\circ}, 1 / \mathrm{f}$ magnitude dependence); around $60 \mathrm{kHz}$, when the phase crosses $0^{\circ}$, there is the resonance; at larger frequency as the phase increases toward $+90^{\circ}$, the magnitude starts to increase, with the circuit working like a pure inductor, as expected for this kind of circuit, at high frequency. The values extracted from the curve are an inductance $L=0.1$ $\mathrm{H}$, a capacitance $\mathrm{C}=68 \mathrm{pF}$ and a resistance $\mathrm{R}=590 \mathrm{k} \Omega$. 

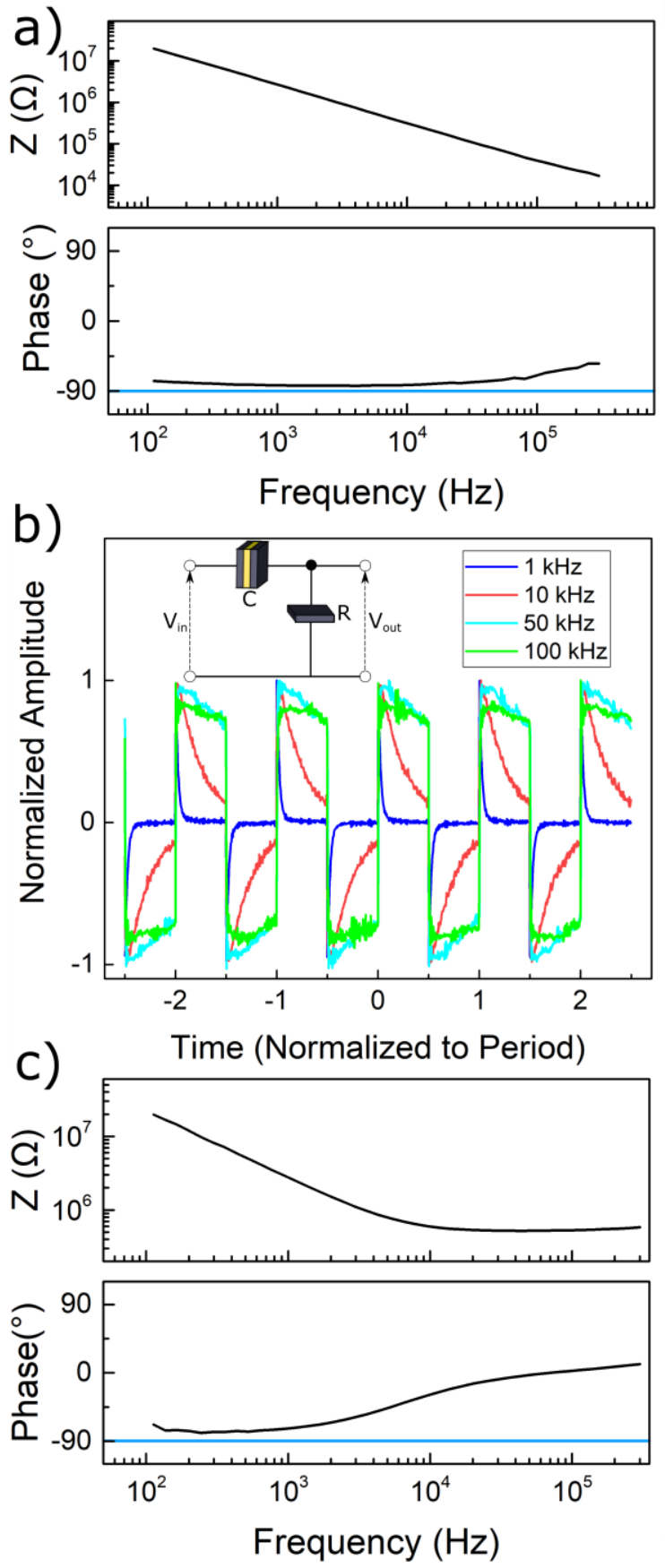

Figure 3: a) impedance of the capacitor as a function of frequency; b) time domain response of a highpass circuit to a square wave at various frequencies; c) impedance of the LCR circuit as a function of frequency, magnitude (upper panel) and phase (lower panel).

\section{Fabrication and characterization of the flexible electrodes}

Electronics designers are willing to convert rigid components and apparats to flexible, soft, wearable and conformable structures. ${ }^{25}, 27,28$ Such transformation will revolutionize electronic devices and the interaction of human beings among each 
other's and with the surrounding environment. The ongoing transition could produce breakthrough in fields as diverse as robotics, architecture, mobile telephony, sports, energy, medicine, automotive and fashion. ${ }^{25,27,28}$ Next, the keratin-graphene water dispersion was used as an ink, to impregnate flexible substrates, such as cellulose, to create soft, flexible electrodes. Conductive cellulose substrates are particularly interesting for flexible and sustainable applications. 1, 25, 27, 29-32 The water-based keratin ink is easy to handle, it is prepared without using organic solvents and complicated multistep manufacturing techniques, a drawback of many of the processes reported in literature for flexible cellulose-based electronics. ${ }^{23,}$ 25, 33 Furthermore, keratin helps PVP stabilizing the GnPs suspension, due to the increase of viscosity and a more negative zeta potential (Table S1), and acts as a matrix, eliminating the needs for adhesive additives ${ }^{34}$ or non-biodegradable plastics, ${ }^{35}$ that hamper the green nature of cellulose. Finally, the use of GnPs instead of metal nanoparticles as conductive fillers, has the advantage of the superior chemical stability of the former. ${ }^{36-39}$

To the best of our knowledge, it is the first time that cellulose is functionalized with a water-based conductive ink derived by waste material. The ink was produced by diluting the water-based keratin achieving a $5 \mathrm{mg} / \mathrm{ml}$ keratin solution in $\mathrm{H}_{2} \mathrm{O}$ and diverse amount of GnPs were added. After tip sonication, the ink was drop casted on cellulose and quickly dried with a heat gun. As shown by the thermogravimetric analysis reported in Figure S4, the heat gun drying does not cause any degradation of the protein matrix. The flexible conductors were homogeneously coated, as shown in Figure $4 a$. The pores of the cellulose were seized by the keratin and graphene composite and the functionalized cellulose surface appeared smoothed, as displayed in Figure 4c, with respect to the rough pure cellulose surface reported in Figure 4b. The sample thickness, after keratin graphene impregnation, increased from $40 \mu \mathrm{m}$ to 
around 50-60 $\mu \mathrm{m}$. The impregnated nanocomposite was more compact, as shown in the cross-section images of Figure S5, thanks to the protein coating.

The electrical percolation threshold was found to be between 3 and 5 wt.\% GnPs with respect to the keratin in a dry basis, where the sheet resistance dropped from $10^{9} \Omega / s q$ to $10^{4}-10^{5} \Omega / \mathrm{sq}$. The flexible biocomposite became an electrical conductor at around 5 wt.\% GnPs concentration, exhibiting ohmic I-V curves, as shown in Figure S3. At 10 wt. $\% \mathrm{GnPs}$ the sheet resistances reach $\approx 10^{3} \Omega /$ sq and further decrease to tens of $\Omega / \mathrm{sq}$ at 30 wt. \% GnPs concentrations.

The stability of the conductivity to severe bending, a key property for flexible and conformable electronics, was investigated before and after repeated folding-unfolding cycles of the keratin-cellulose samples with $30 \mathrm{wt} \% \mathrm{GnPs}$. The biocomposites were pressed with a $2 \mathrm{~kg}$ weight along the fold line to enhance the stress experienced at each cycle. ${ }^{19,20,30}$ The ratio $R_{i} / R_{0}$ represents the variation after each cycle and is displayed in Figure 4e. The resistance of the material increased only of about the $30 \%$ after 20 folding events. Such results are remarkable and significantly better compared to previous reported works, where the samples underwent similar folding events. ${ }^{25} \mathrm{At}$ the fold line the microstructure showed cracks on the samples' surface, as shown in Figure S6. It is significant that, despite the cracks, the material maintained a remarkable level of conductivity. Indeed, the performance drop did not compromise the operation of LEDs at $12 \mathrm{~V}$ voltage using two flexible nanocomposite electrodes, also after folding and crumpling as shown in Figure S7. This result is achievable thanks to the cellulose-like mechanical properties of the protein-based composite as shown in Figure S8 and Table S4. 
a)
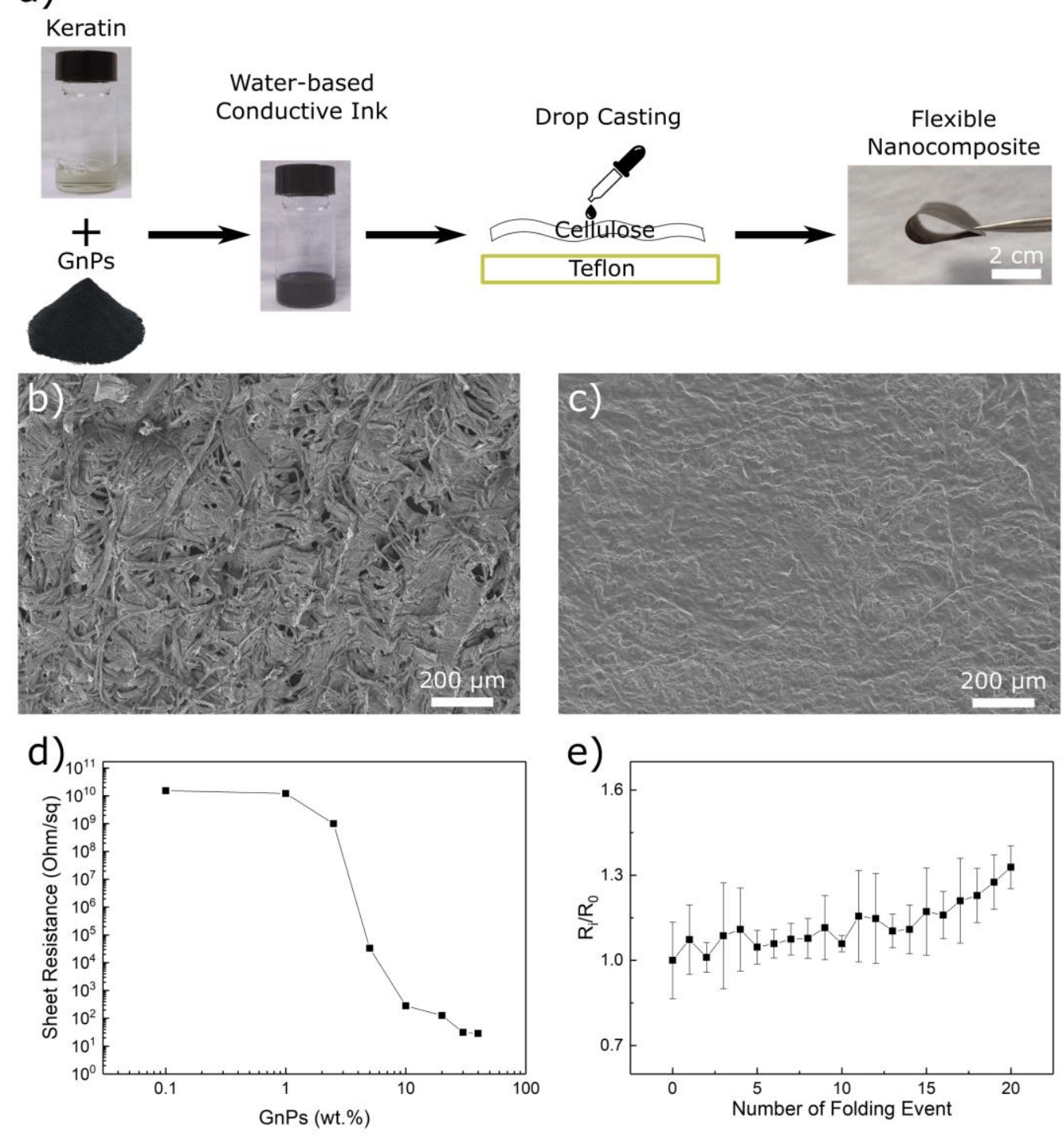

e)

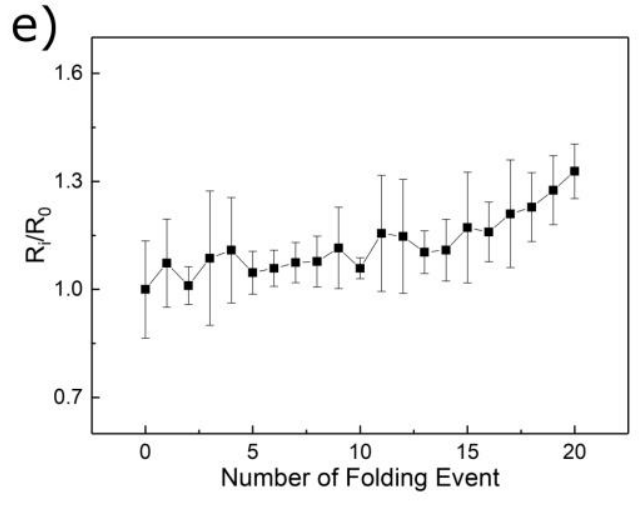

Figure 4: a) fabrication scheme of the keratin-GnPs flexible electrode; b) and c) SEM morphology of the pure cellulose before and after functionalization with keratin-GnPs ink, respectively; d) sheet resistance of the material versus GnPs wt.\%; e) variation of the electrical resistance of the conductor with folding-unfolding cycles.

\section{Conclusion}

In conclusion, keratin extracted from waste wool clips was combined with graphene nanoplatelets obtaining a material with suitable properties for electronics. Being all based on water solutions and low temperature treatments, the proposed approach is simple and green. Resistor with on demand sheet resistance (from tens of $\Omega / s q$ to $\mathrm{M} \Omega / \mathrm{sq}$ ) could be obtained tuning the conductive nanofillers load. The waste-based 
conductor could become extremely soft with humidity conditioning, allowing it to adhere to protein dielectric layers, conform to complex shapes with small curvature radius and enabling the fabrication of protein-based capacitor and inductors. Basic circuits could be assembled coupling the waste-based resistors, capacitors and inductors implementing for example filters, resonators, or integrator/differentiators. A high-pass filter was assembled as proof of concept. The fabrication of these discrete electrical components (resistors, capacitors, inductors) and of analogue devices can provide the groundwork for the fabrication of biodegradable electronic apparatus such as PCBs and electronic interfaces. The functionalization of cellulose sheets with the conductive protein-GnP composite boosts the application of this approach also in flexible and wearable electronics. The demonstration of the adaptability of the composite systems towards different electronic components, together with previous reports on microfabrication and nanofabrication of protein composites, ${ }^{8,30,40}$ show the way for downscaling these components to create microelectronic devices. The developed wastetronics are an excellent example of a circular economy system because they are high added value materials coming from a waste stream that is currently underutilized, while simultaneously they provide electronic manufacturers with the possibility to introduce a degree of sustainability in electronics.

\section{Supporting Information}

Characterization results of Profilometry, TGA, Capacitor Features, High Magnification SEM and Mechanical Properties of the material.

\section{Acknowledgements}

The authors acknowledge Lara Marini for the help with the thermogravimetric analysis measurements. The authors acknowledge Directa Plus S.P.A. for kindly providing the 
graphene nanoplatelets. The authors acknowledge also Luca Ceseracciu and the

Materials Characterization Facility of the Istituto Italiano di Tecnologia.

\section{References:}

1. Jung, Y. H.; Chang, T. H.; Zhang, H.; Yao, C.; Zheng, Q.; Yang, V. W.; Mi, H.; Kim, M.; Cho, S. J.; Park, D. W.; Jiang, H.; Lee, J.; Qiu, Y.; Zhou, W.; Cai, Z.; Gong, S.; Ma, Z., High-performance green flexible electronics based on biodegradable cellulose nanofibril paper. Nat Commun 2015, 6, 7170 .

2. Irimia-Vladu, M.; Glowacki, E. D.; Voss, G.; Bauer, S.; Sariciftci, N. S., Green and biodegradable electronics. Materials Today 2012, 15 (7-8), 340-346.

3. Logan, B. E., Waste Not, Want It. Environmental Science \& Technology Letters 2018, 5 (6), 301-301.

4. $\quad$ Balde, C. P.; Forti, V.; Gray, V.; Kuehr, R.; Stegmann, P., The global e-waste monitor 2017: Quantities, flows and resources. United Nations University, International Telecommunication Union: 2017.

5. Irimia-Vladu, M.; Glowacki, E. D.; Sariciftci, N. S.; Bauer, S., Green Materials for Electronics. John Wiley \& Sons: 2017.

6. Irimia-Vladu, M., "Green" electronics: biodegradable and biocompatible materials and devices for sustainable future. Chem Soc Rev 2014, 43 (2), 588-610.

7. Baumgartner, M.; Coppola, M. E.; Sariciftci, N. S.; Glowacki, E. D.; Bauer, S.; Irimia-Vladu, M., Emerging "Green" Materials and Technologies for Electronics. Green Materials for Electronics 2017, 101.

8. Tseng, P.; Perotto, G.; Napier, B.; Riahi, P.; Li, W.; Shirman, E.; Kaplan, D. L.; Zenyuk, I. V.; Omenetto, F. G., Silk Fibroin-Carbon Nanotube Composite Electrodes for Flexible Biocatalytic Fuel Cells. Advanced Electronic Materials 2016, 2 (8).

9. Seo, H.-K.; Kim, T.-S.; Park, C.; Xu, W.; Baek, K.; Bae, S.-H.; Ahn, J.-H.; Kim, K.; Choi, H. C.; Lee, T.-W., Value-added synthesis of graphene: recycling industrial carbon waste into electrodes for high-performance electronic devices. Scientific reports 2015, 5, 16710.

10. Gustavsson, J.; Cederberg, C.; Sonesson, U.; Van Otterdijk, R.; Meybeck, A., Global food losses and food waste. FAO Rome: 2011.

11. Ferraro, V.; Anton, M.; Santé-Lhoutellier, V., The "sisters" $\alpha$-helices of collagen, elastin and keratin recovered from animal by-products: Functionality, bioactivity and trends of application. Trends in Food Science \& Technology 2016, 51, 65-75.

12. Reddy, N.; Jiang, Q.; Jin, E.; Shi, Z.; Hou, X.; Yang, Y., Bio-thermoplastics from grafted chicken feathers for potential biomedical applications. Colloids Surf B Biointerfaces 2013, 110, 51-8. 13. Lee, H.; Noh, K.; Lee, S. C.; Kwon, I.-K.; Han, D.-W.; Lee, I.-S.; Hwang, Y.-S., Human hair keratin and its-based biomaterials for biomedical applications. Tissue Engineering and Regenerative Medicine 2014, 11 (4), 255-265.

14. Dou, Y.; Huang, X.; Zhang, B. N.; He, M.; Yin, G. Q.; Cui, Y. D., Preparation and characterization of a dialdehyde starch crosslinked feather keratin film for food packaging application. Rsc Adv 2015, 5 (34), 27168-27174.

15. Ullah, A.; Vasanthan, T.; Bressler, D.; Elias, A. L.; Wu, J., Bioplastics from feather quill. Biomacromolecules 2011, 12 (10), 3826-32.

16. Cataldi, P.; Bayer, I. S.; Nanni, G.; Athanassiou, A.; Bonaccorso, F.; Pellegrini, V.; Castillo, A. E. D.; Ricciardella, F.; Artyukhin, S.; Tronche, M. A.; Gogotsi, Y.; Cingolani, R., Effect of graphene nano-platelet morphology on the elastic modulus of soft and hard biopolymers. Carbon 2016, 109, 331-339. 
17. Yamauchi, K.; Yamauchi, A.; Kusunoki, T.; Kohda, A.; Konishi, Y., Preparation of stable aqueous solution of keratins, and physiochemical and biodegradational properties of films. Journal of Biomedical Materials Research: An Official Journal of The Society for Biomaterials and The Japanese Society for Biomaterials 1996, 31 (4), 439-444.

18. Rockwood, D. N.; Preda, R. C.; Yücel, T.; Wang, X.; Lovett, M. L.; Kaplan, D. L., Materials fabrication from Bombyx mori silk fibroin. Nature protocols 2011, 6 (10), 1612.

19. Cataldi, P.; Bayer, I. S.; Bonaccorso, F.; Pellegrini, V.; Athanassiou, A.; Cingolani, R., Foldable Conductive Cellulose Fiber Networks Modified by Graphene Nanoplatelet-Bio-Based Composites. Advanced Electronic Materials 2015, 1 (12), 1500224.

20. Cataldi, P.; Bonaccorso, F.; Esau del Rio Castillo, A.; Pellegrini, V.; Jiang, Z.; Liu, L.; Boccardo, N.; Canepa, M.; Cingolani, R.; Athanassiou, A., Cellulosic Graphene Biocomposites for Versatile High-Performance Flexible Electronic Applications. Advanced Electronic Materials 2016, 2 (11), 1600245.

21. Cataldi, P.; Ceseracciu, L.; Marras, S.; Athanassiou, A.; Bayer, I. S., Electrical conductivity enhancement in thermoplastic polyurethane-graphene nanoplatelet composites by stretch-release cycles. Applied Physics Letters 2017, 110 (12), 121904.

22. Stankovich, S.; Dikin, D. A.; Dommett, G. H.; Kohlhaas, K. M.; Zimney, E. J.; Stach, E. A.; Piner, R. D.; Nguyen, S. T.; Ruoff, R. S., Graphene-based composite materials. Nature 2006, 442 (7100), 282-6.

23. Cataldi, P.; Ceseracciu, L.; Athanassiou, A.; Bayer, I. S., Healable Cotton-Graphene Nanocomposite Conductor for Wearable Electronics. ACS applied materials \& interfaces 2017, 9 (16), $13825-13830$.

24. Cataldi, P.; Dussoni, S.; Ceseracciu, L.; Maggiali, M.; Natale, L.; Metta, G.; Athanassiou, A.; Bayer, I. S., Carbon Nanofiber versus Graphene-Based Stretchable Capacitive Touch Sensors for Artificial Electronic Skin. Adv Sci (Weinh) 2018, 5 (2), 1700587.

25. Cataldi, P.; Athanassiou, A.; Bayer, I. S., Graphene Nanoplatelets-Based Advanced Materials and Recent Progress in Sustainable Applications. Applied Sciences-Basel 2018, 8 (9), 1438.

26. Kim, C.-H.; Pyun, S.-I.; Kim, J.-H., An investigation of the capacitance dispersion on the fractal carbon electrode with edge and basal orientations. Electrochimica Acta 2003, 48 (23), 34553463.

27. Zeng, W.; Shu, L.; Li, Q.; Chen, S.; Wang, F.; Tao, X. M., Fiber-based wearable electronics: a review of materials, fabrication, devices, and applications. Adv Mater 2014, 26 (31), 5310-36.

28. Jang, H.; Park, Y. J.; Chen, X.; Das, T.; Kim, M. S.; Ahn, J. H., Graphene-Based Flexible and Stretchable Electronics. Adv Mater 2016, 28 (22), 4184-202.

29. Wang, C.; Wang, C.; Huang, Z.; Xu, S., Materials and Structures toward Soft Electronics. Adv Mater 2018, 30 (50), e1801368.

30. Cataldi, P.; Heredia-Guerrero, J. A.; Guzman-Puyol, S.; Ceseracciu, L.; La Notte, L.; Reale, A.; Ren, J.; Zhang, Y.; Liu, L.; Miscuglio, M.; Savi, P.; Piazza, S.; Duocastella, M.; Perotto, G.; Athanassiou, A.; Bayer, I. S., Sustainable Electronics Based on Crop Plant Extracts and Graphene: A "Bioadvantaged" Approach. Advanced Sustainable Systems 2018, 1800069.

31. La Notte, L.; Cataldi, P.; Ceseracciu, L.; Bayer, I. S.; Athanassiou, A.; Marras, S.; Villari, E.; Brunetti, F.; Reale, A., Fully-sprayed flexible polymer solar cells with a cellulose-graphene electrode. Materials Today Energy 2018, 7, 105-112.

32. Hyun, W. J.; Park, O. O.; Chin, B. D., Foldable graphene electronic circuits based on paper substrates. Adv Mater 2013, 25 (34), 4729-34.

33. Kamyshny, A.; Magdassi, S., Conductive nanomaterials for printed electronics. Small 2014, 10 (17), 3515-35.

34. Secor, E. B.; Gao, T. Z.; Islam, A. E.; Rao, R.; Wallace, S. G.; Zhu, J.; Putz, K. W.; Matuyama, B.; Hersam, M. C., Enhanced Conductivity, Adhesion, and Environmental Stability of Printed Graphene Inks with Nitrocellulose. Chemistry of Materials 2017, 29 (5), 2332-2340. 
35. Karim, N.; Afroj, S.; Malandraki, A.; Butterworth, S.; Beach, C.; Rigout, M.; Novoselov, K. S.; Casson, A. J.; Yeates, S. G., All inkjet-printed graphene-based conductive patterns for wearable etextile applications. Journal of Materials Chemistry C 2017, 5 (44), 11640-11648.

36. Yang, W. D.; Wang, C. H., Graphene and the related conductive inks for flexible electronics. Journal of Materials Chemistry C 2016, 4 (30), 7193-7207.

37. Parnell, C. M.; Chhetri, B. P.; Mitchell, T. B.; Watanabe, F.; Kannarpady, G.; RanguMagar, A. B.; Zhou, H.; Alghazali, K. M.; Biris, A. S.; Ghosh, A., simultaneous electrochemical Deposition of Cobalt Complex and poly (pyrrole) thin Films for supercapacitor electrodes. Scientific reports 2019, 9 (1), 5650.

38. Parnell, C. M.; Chhetri, B.; Brandt, A.; Watanabe, F.; Nima, Z. A.; Mudalige, T. K.; Biris, A. S.; Ghosh, A., Polydopamine-coated manganese complex/graphene nanocomposite for enhanced electrocatalytic activity towards oxygen reduction. Scientific reports 2016, 6, 31415.

39. Gartia, Y.; Parnell, C. M.; Watanabe, F.; Szwedo, P.; Biris, A. S.; Peddi, N.; Nima, Z. A.; Ghosh, A., Graphene-enhanced oxygen reduction by MN4 type cobalt (III) catalyst. ACS Sustainable Chemistry \& Engineering 2014, 3 (1), 97-102.

40. Perotto, G.; Cittadini, M.; Tao, H.; Kim, S.; Yang, M.; Kaplan, D. L.; Martucci, A.; Omenetto, F. G., Fabrication of Tunable, High-Refractive-Index Titanate-Silk Nanocomposites on the Micro-and Nanoscale. Advanced Materials 2015, 27 (42), 6728-6732. 


\section{Table of Content}

Keratin extracted from waste wool clips is repurposed in an electronic material, boosting circular economy approach in the electronics sector and contributing in the development of sustainable electronics products with reduced fingerprint on the environment.

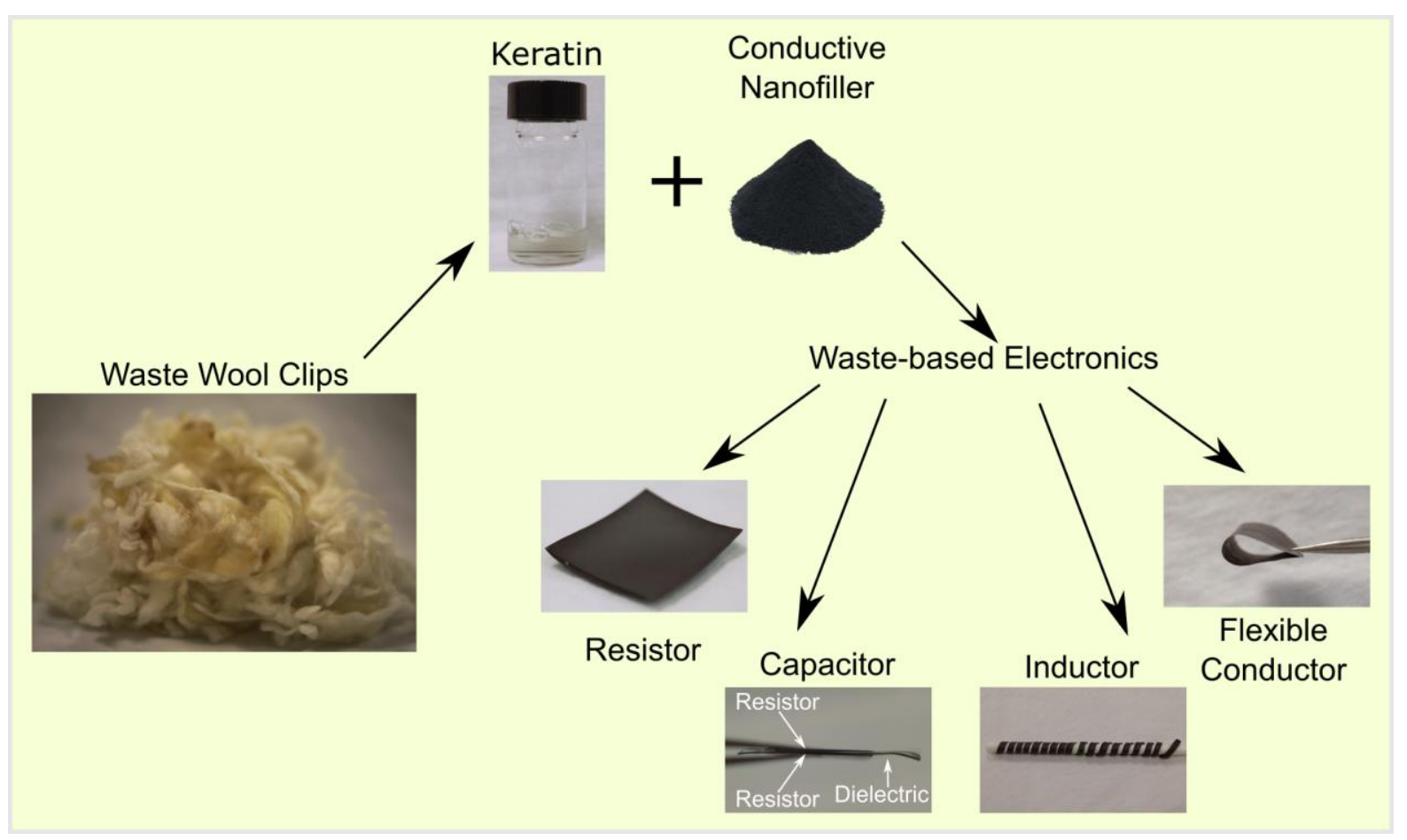




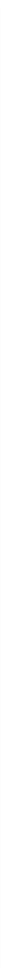


a)

Wool Waste
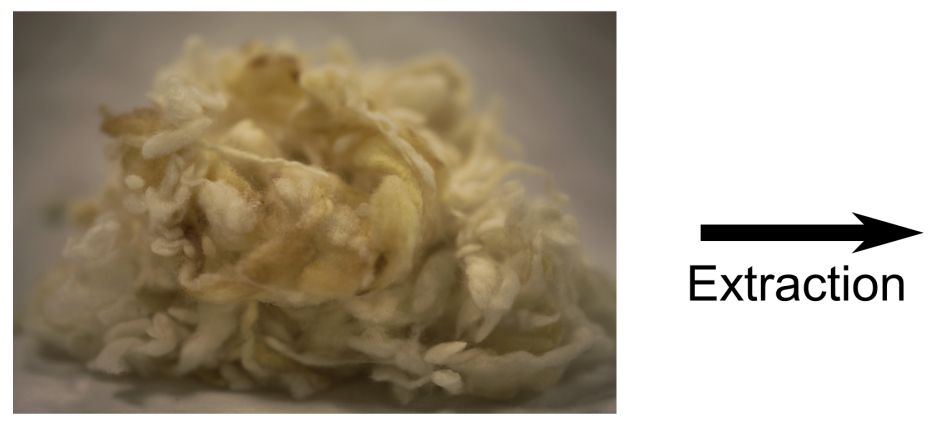

Waste-based Conductor
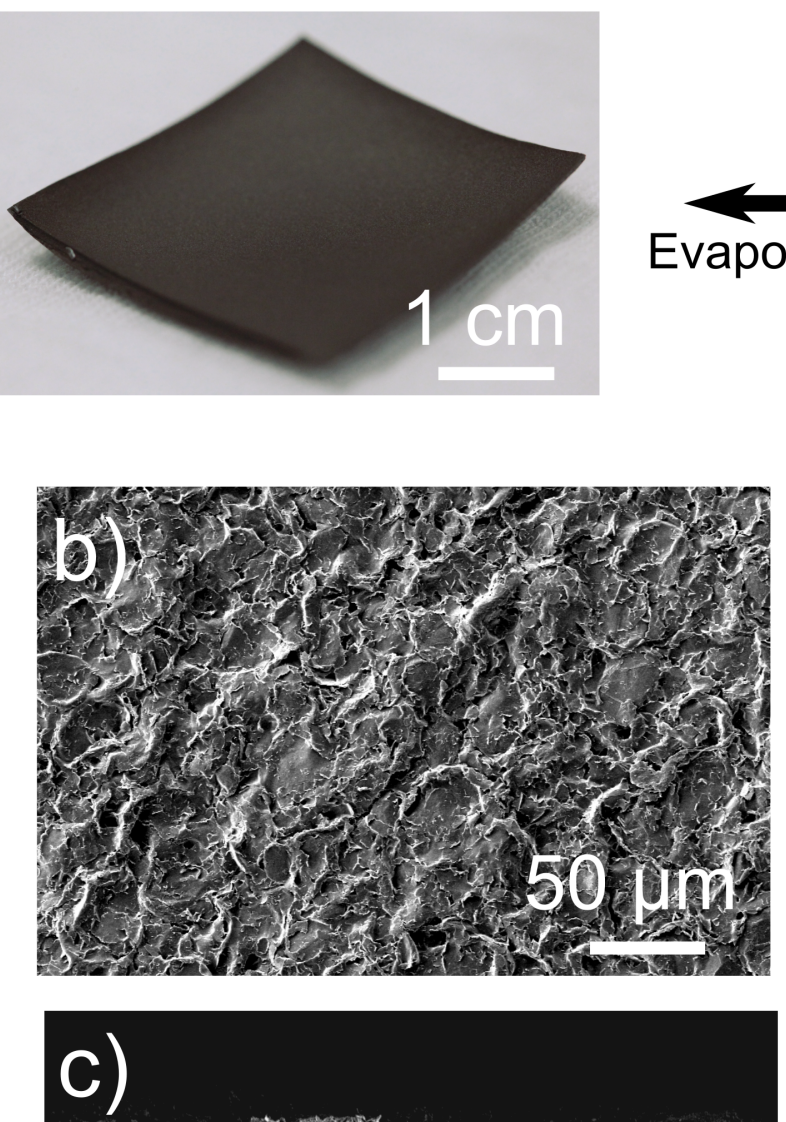

46
ACS Sustainable Chemistry \& Engineering

Keratin
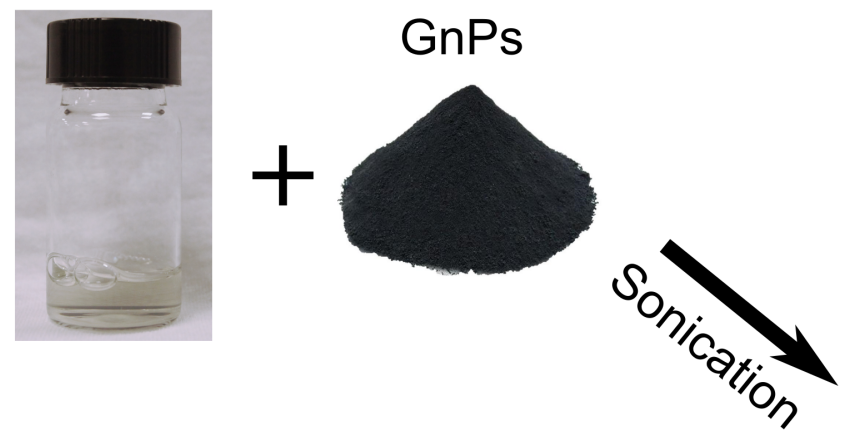

Water-based Conductive Ink
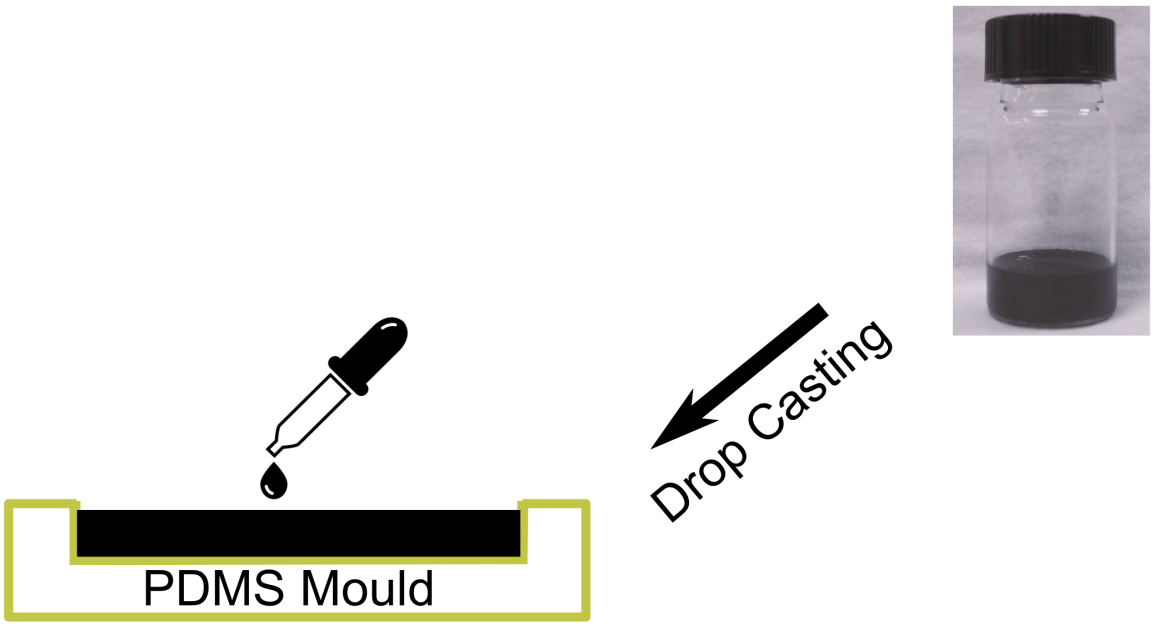

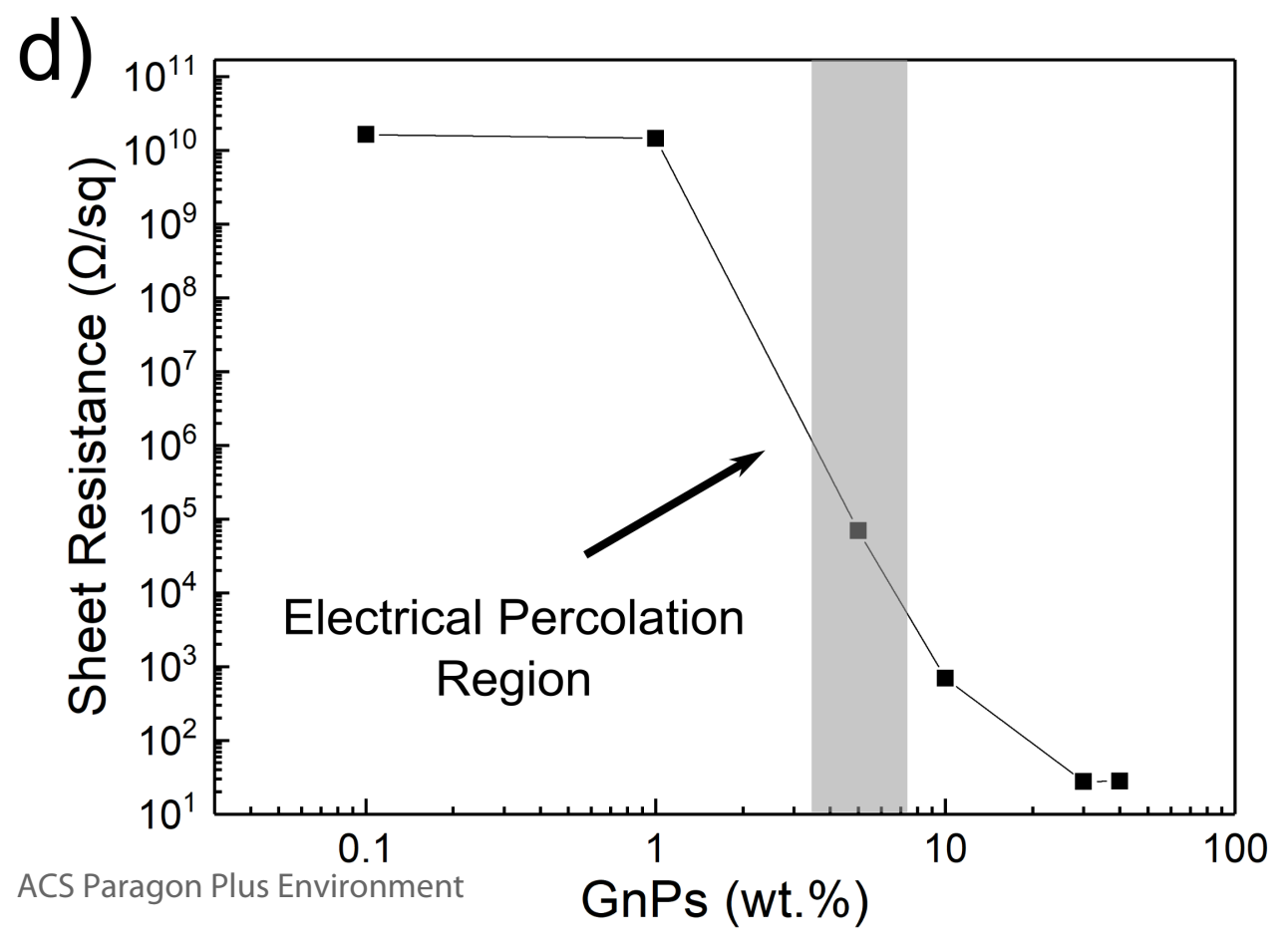




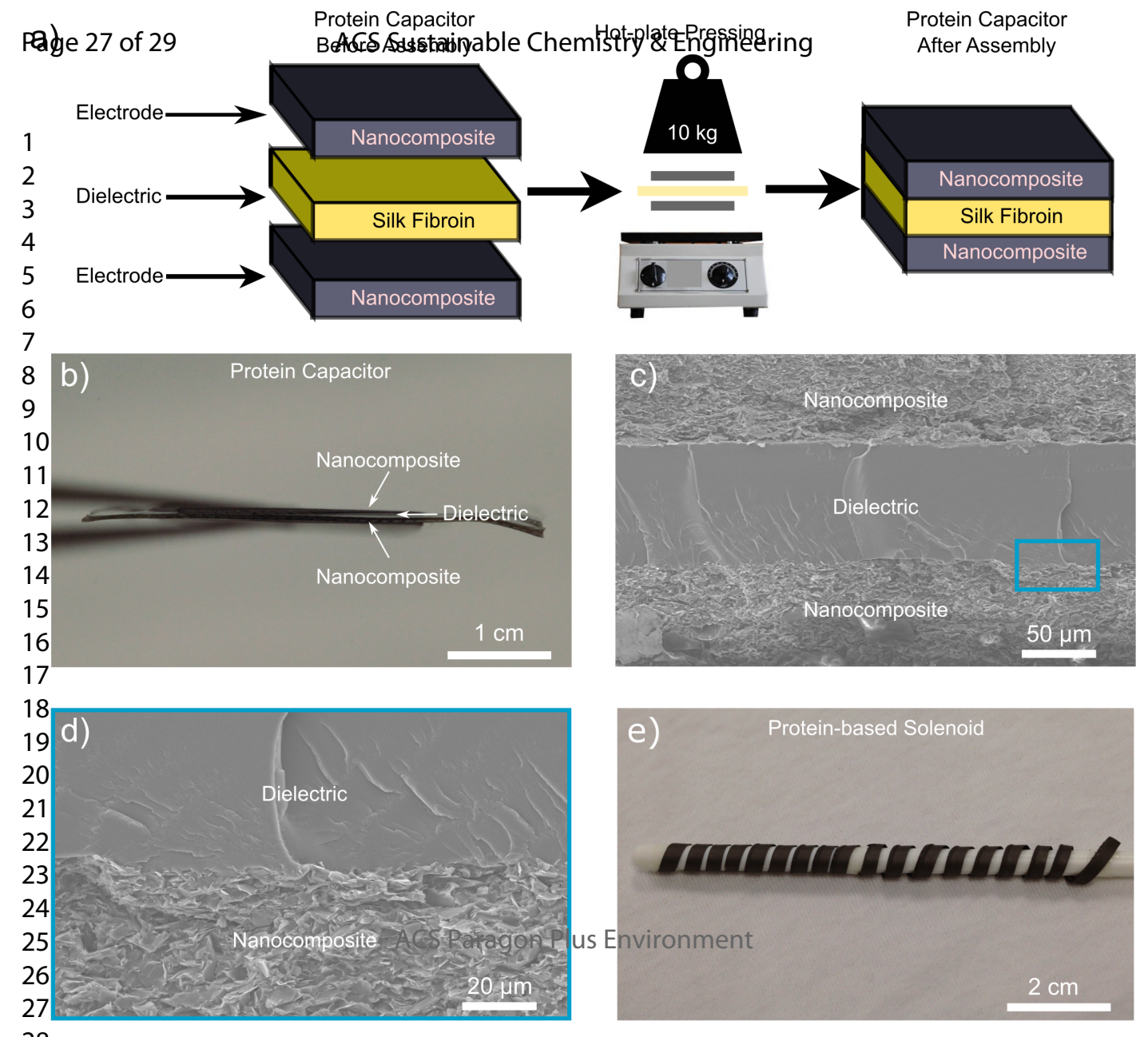




\section{Pakgezin of 29 ACS Sustainable Chemistry \& Engineering}

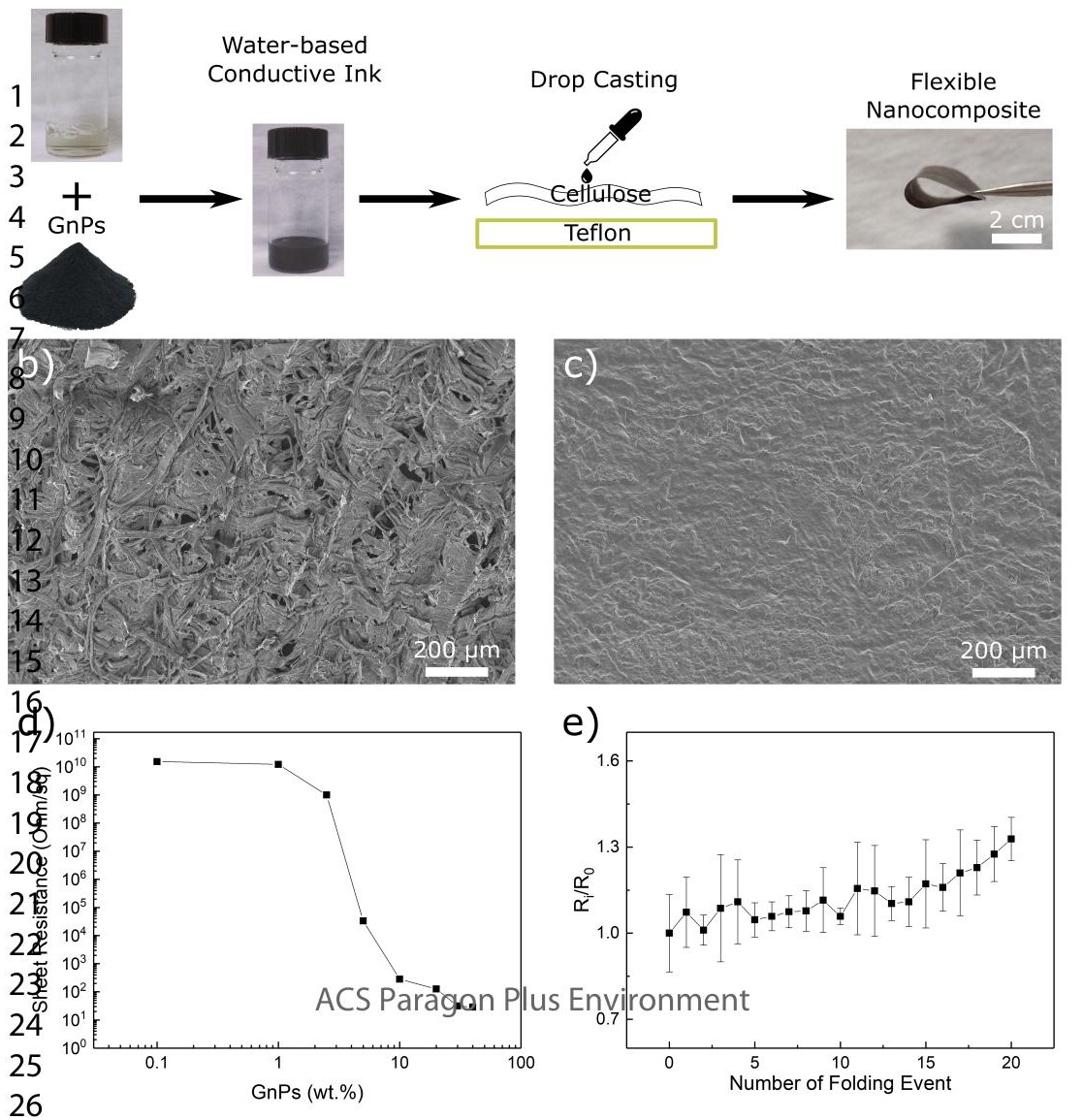

